\title{
Mitigation of methane production from cattle by feeding cashew nut shell liquid
}

\author{
T. Shinkai, ${ }^{\star}$ O. Enishi, ${ }^{\star}$ M. Mitsumori, ${ }^{*}$ K. Higuchi, ${ }^{\star}$ Y. Kobayashi, ${ }^{\star}$ A. Takenaka, ${ }^{\star}$ K. Nagashima, $\dagger$ \\ M. Mochizuki,† and Y. Kobayashi ${ }^{1}$ \\ *National Institute of Livestock and Grassland Science, Ibaraki 305-0901, Japan \\ †Environment and Biotechnology Laboratory, Idemitsu Kosan Co. Ltd., Sodegaura 299-0293, Japan \\ $\ddagger$ Research Faculty of Agriculture, Hokkaido University, Hokkaido 060-8589, Japan
}

\section{ABSTRACT}

The effects of cashew nut shell liquid (CNSL) feeding on methane production and rumen fermentation were investigated by repeatedly using 3 Holstein nonlactating cows with rumen fistulas. The cows were fed a concentrate and hay diet (6:4 ratio) for $4 \mathrm{wk}$ (control period) followed by the same diet with a CNSL-containing pellet for the next $3 \mathrm{wk}$ (CNSL period). Two trials were conducted using CNSL pellets blended with only silica (trial 1) or with several other ingredients (trial 2). Each pellet type was fed to cows to allow CNSL intake at $4 \mathrm{~g} / 100 \mathrm{~kg}$ of body weight per day. Methane production was measured in a respiration chamber system, and energy balance, nutrient digestibility, and rumen microbial changes were monitored. Methane production per unit of dry matter intake decreased by 38.3 and $19.3 \%$ in CNSL feeding trials 1 and 2, respectively. Energy loss as methane emission decreased from 9.7 to $6.1 \%$ (trial 1) and from 8.4 to $7.0 \%$ (trial 2) with CNSL feeding, whereas the loss to feces (trial 1) and heat production (trial 2) increased. Retained energy did not differ between the control and CNSL periods. Digestibility of dry matter and gross energy decreased with CNSL feeding in trial 1, but did not differ in trial 2. Feeding CNSL caused a decrease in acetate and total short-chain fatty acid levels and an increase in propionate proportion in both trials. Relative copy number of methyl coenzyme-M reductase subunit A gene and its expression decreased with CNSL feeding. The relative abundance of fibrolytic or formate-producing species such as Ruminococcus flavefaciens, Butyrivibrio fibrisolvens, and Treponema bryantii decreased, but species related to propionate production, including Prevotella ruminicolla, Selenomonas ruminantium, Anaerovibrio

Received March 21, 2012.

Accepted May 4, 2012.

${ }^{1}$ Corresponding author: kyas@anim.agr.hokudai.ac.jp lipolytica, and Succinivibrio dextrinosolvens, increased. If used in a suitable formulation, CNSL acts as a potent methane-inhibiting and propionate-enhancing agent through the alteration of rumen microbiota without adversely affecting feed digestibility.

Key words: rumen, methane, feed additive, cashew nut shell liquid

\section{INTRODUCTION}

Methane is one of the major greenhouse gases released to the atmosphere, and its direct global warming potential is 23 times that of carbon dioxide (FAO, 2007). Enteric fermentation in ruminants is one of the largest sources of methane and is thought to account for 28 to $33 \%$ of global anthropogenic methane emissions (US EPA, 2005; FAO, 2007). In ruminants, methane production principally depends on DMI (Shibata and Terada, 2010), and 2 to $15 \%$ of the gross energy (GE) obtained from feed is lost to methane emissions (Wright et al., 2004). Therefore, several efforts have been focused on decreasing enteric methane production by the addition of lipids, plant compounds, monensin, and other organic compounds, or by otherwise controlling diet composition (Odongo et al., 2007; Hook et al., 2010).

Cashew (Anacardium occidentale) is planted globally, and the liquid obtained by pressing the shells of nuts (cashew nut shell liquid, CNSL) contains a significant amount of naturally occurring anacardic acid, which has antibacterial activities against gram-positive bacteria (Kubo et al., 1993). Recently, we found that CNSL might contain an agent that inhibits methane production in ruminal batch and semicontinuous cultures by up to $70.1 \%$ (Watanabe et al., 2010). At the same time, CNSL was found to enhance propionate production by increasing the proportions of propionate- and succinate-producing rumen bacteria (Watanabe et al., 2010). Although the potency of anacardic acid as a propionate enhancer was pointed out in an simple in vitro study (Van Nevel et al., 1971), more extensive studies 
Table 1. Ingredients and nutrient composition of each experimental diet

\begin{tabular}{|c|c|c|c|c|}
\hline \multirow[b]{2}{*}{ Item } & \multicolumn{2}{|c|}{ Trial 1} & \multicolumn{2}{|c|}{ Trial 2} \\
\hline & Control & $\mathrm{CNSL}^{1}$ & Control & CNSL \\
\hline \multicolumn{5}{|l|}{ Ingredient, $\%$ of DM } \\
\hline Concentrate & 60.0 & 59.1 & 56.1 & 56.1 \\
\hline Timothy hay & 40.0 & 40.0 & 40.6 & 40.6 \\
\hline CNSL pellet $\mathrm{A}^{2}$ & - & 0.9 & - & - \\
\hline CNSL pellet $\mathrm{B}^{3}$ & - & - & - & 1.3 \\
\hline Vehicle pellet $B^{4}$ & - & - & 3.3 & 2.0 \\
\hline DMI, $\mathrm{kg} / \mathrm{d}$ & 6.91 & 6.91 & 7.14 & 7.14 \\
\hline Gross energy, MJ/d & 126.3 & 126.3 & 128.6 & 125.1 \\
\hline \multicolumn{5}{|l|}{ Nutrient composition \% of DM } \\
\hline OM & 94.2 & 93.9 & 93.4 & 93.4 \\
\hline $\mathrm{CP}$ & 12.6 & 12.5 & 12.6 & 12.6 \\
\hline Ether extract & 1.9 & 2.5 & 2.7 & 2.9 \\
\hline NDF & 40.1 & 39.9 & 40.4 & 40.3 \\
\hline
\end{tabular}

${ }^{1}$ Cashew nut shell liquid.

${ }^{2}$ Contained $60 \%$ CNSL and $40 \%$ silica powder.

${ }^{3}$ Contained $22.0 \%$ CNSL, $41.3 \%$ alfalfa meal, $20.0 \%$ defatted rice bran, $11.3 \%$ silica powder, $3.0 \%$ crude sugarcane molasses, and $2.4 \%$ tapioca flour.

${ }^{4}$ Pelleted as CNSL pellet B but without CNSL.

simulating the rumen, such as that by Watanabe et al. (2010) and the in vivo feeding study presented here, are needed to apply CNSL to the animal feed industry.

In the present study, 2 feeding trials were conducted to evaluate the effect of CNSL feeding on methane production, nutrient digestibility, rumen fermentation, and rumen microbiota by repeatedly using 3 cows. The methane-inhibiting potential for using CNSL as a feed additive is discussed.

\section{MATERIALS AND METHODS}

\section{Animals, Diets, Feeding, and CNSL Additive}

Animal care and experiments were conducted according to the guidelines of the Animal Care Committee of the National Institute of Livestock and Grassland Science, Tsukuba, Japan. Three ruminally fistulated, nonlactating Holstein cows were repeatedly used in 2 feeding trials (mean BW of $547 \pm 31 \mathrm{~kg}$ for trial 1 and $548 \pm 27 \mathrm{~kg}$ for trial 2). Cows were kept individually in stalls and fed a basal diet consisting of a concentrate and timothy (Phleum pratense) hay chopped in $5-\mathrm{cm}$ lengths in a 6:4 ratio twice a day (0930 and $1630 \mathrm{~h})$ to meet 1.3 times the maintenance energy requirement from the 2006 Japanese feeding standard (NARO, 2006) for dairy cattle (Table 1). The concentrate was a mixture of corn powder, 30\%; barley powder, $25 \%$; soybean meal, $11.7 \%$; wheat bran, $9 \%$; defatted rice bran, $7 \%$; alfalfa meal, $7 \%$; beet pulp, $5 \%$; molasses, $3.5 \%$; calcium carbonate, $1.2 \%$; sodium chloride, $0.5 \%$; and vitamin premix, $0.1 \%$. The concentrate contained
93.7\% OM, 24.3\% NDF, $18.5 \% \mathrm{CP}$, and $6.3 \%$ crude ash. The concentrate and hay were sampled during each experiment and subjected to nutrient analyses.

Raw CNSL mechanically pressed from cashew nut shells (grown in India), having a chemical composition as described previously (Watanabe et al., 2010), was provided by Idemitsu Kosan Co. Ltd. (Tokyo, Japan). Two types of pellets (pellets A and B) were formulated for the feeding trials. The CNSL was mixed with silica powder (6:4) and pelleted (pellet A) for the use in trial 1. To improve palatability (see Results section), CNSL was mixed with alfalfa meal (41.3\%), defatted rice bran (20.0\%), silica powder (11.3\%), crude sugarcane molasses (3.0\%), and tapioca flour $(2.4 \%)$ and pelleted (pellet B) for use in trial 2. Both pellets had a diameter of $5 \mathrm{~mm}$. The final concentration of CNSL in pellets A and B was 60 and $22 \%$, respectively. Vehicle pellet B was prepared with the same feed ingredients as pellet $\mathrm{B}$, except for CNSL, and was fed as a control additive in trial 2 (Table 1 ). The pellets were stored at $4^{\circ} \mathrm{C}$ in the dark until use.

\section{Experimental Design and Samplings}

The cows were fed a basal diet without CNSL (trial 1 ) or with the addition of vehicle pellet $B$ (trial 2) for $4 \mathrm{wk}$ (control period), and then the same diet was supplemented with CNSL pellet (pellets A and B for trials 1 and 2, respectively) for 3 wk (CNSL period). Because the residual effect of CNSL on rumen microbiota and fermentation profile was uncertain, the CNSL treatment period occurred after the control period. The 
same design was used in other reports dealing with antimicrobial materials with uncertain residual effects on the rumen (Edwards et al., 2005; Denman et al., 2007). To erase or minimize a possible effect of period, the cows in the present experiment were managed under strictly fixed hydrothermal conditions $\left(20^{\circ} \mathrm{C}, 60 \%\right.$ humidity) throughout the experiment.

Sampling was performed on the last $5 \mathrm{~d}$ of each period. Cows were placed in the fully automated whole-body respiration chamber as outlined by Iwasaki et al. (1982) during the sampling period, where gas measurements were made on the first 3 consecutive days. The respiration chamber was maintained at a controlled temperature and humidity (see above) with an aeration flow of $600 \mathrm{~L} / \mathrm{min}$ throughout the experiment. Temperature $\left({ }^{\circ} \mathrm{C}\right)$, humidity (\%), and atmospheric pressure $\left(\mathrm{mm} \mathrm{H}_{2} \mathrm{O}\right)$ of inlet and outlet air of the chamber system were monitored to calculate net volume of gases, including $\mathrm{O}_{2}, \mathrm{CO}_{2}$, and $\mathrm{CH}_{4}$ (DO9861T-R1, Delta Ohm, Padua, Italy, for temperature and relative humidity; Puncture pressure, Nagano Keiki Seisakusho, Tokyo, Japan, for atmospheric pressure). Concentrations of $\mathrm{CH}_{4}, \mathrm{CO}_{2}$, and $\mathrm{O}_{2}$ in the inlet and outlet air of chamber were measured every 6 min by infrared radiation sensor systems (VA-300 Gas analyzer, Horiba, Kyoto, Japan, for $\mathrm{CH}_{4}$ and $\mathrm{CO}_{2}$; Xentra 4100 Gas Purity Analyzer, Servomex, Crowborough, UK, for $\mathrm{O}_{2}$ ). The data set of the gases was collected by computer and used to calculate heat production (HP) according to Brouwer (1965), as follows: $\mathrm{HP}(\mathrm{kJ})=4.184 \times\left[3.866 \times \mathrm{O}_{2}(\mathrm{~L})+1.200 \times\right.$ $\mathrm{CO}_{2}(\mathrm{~L})-0.518 \times \mathrm{CH}_{4}(\mathrm{~L})-1.431 \times$ urine-N $\left.(\mathrm{g})\right]$, where urine- $\mathrm{N}$ data were based on separate chemical analysis (described below). Calculated HP was used to estimate retained energy derived as follows: Retained energy $(\mathrm{kJ})=\mathrm{GE}$ - feces $(\mathrm{kJ})$ - urine $(\mathrm{kJ})$ - methane $(\mathrm{kJ})$ - HP $(\mathrm{kJ})$ - milk (kJ). In the present study, energy in the parameter "milk" was neglected.

Total feces and urine were collected on all 5 sampling days. Urine was collected in buckets containing $300 \mathrm{~g}$ of $20 \% \mathrm{H}_{2} \mathrm{SO}_{4}(\sim 0.01 \%$ of daily urine output). During the experimental period, daily feces and urine outputs were collected and weighed. Feces were mechanically mixed (MIX-881, Hitachi, Tokyo, Japan) to obtain homogeneous samples. Urine was filtered through 2 layers of cheese cloth. Subsamples of each daily output were taken and combined for each cow. The combined fecal sample was dried at $60^{\circ} \mathrm{C}$ for $48 \mathrm{~h}$, milled to pass a 1-mm screen (SM-2000, Retsch, Haan, Germany), and used for analyses. The combined urine sample was frozen at $-30^{\circ} \mathrm{C}$ until analysis. Rumen content was collected before the morning feeding via a rumen cannula on the first and last days of a 3-d gas measurement period, filtered through 4 layers of cheese cloth, stored at $-80^{\circ} \mathrm{C}$, and mixed before analyzing rumen fermentation products, protozoa, and bacteria.

The feeding level was set at $4 \mathrm{~g}$ of CNSL per $100 \mathrm{~kg}$ of BW per day, a level that had been experimentally defined as being effective in sheep (Y. Kobayashi, unpublished data). The total amount of CNSL pellet fed to each cow ranged from 36 to 39 and from 96 to 104 $\mathrm{g} / \mathrm{d}$ in trials 1 and 2, respectively. The daily allotment of each pellet was equally divided into 2 portions and given together with the basal diet at twice-daily feedings.

\section{Chemical and Microbial Analysis}

Basal diet, CNSL pellets, and feces were chemically analyzed for DM, CP, ether extract, ash, and NDF (AOAC, 1990; Van Soest et al., 1991). Gross energy was determined in an adiabatic bomb calorimeter (CA4PJ, Shimadzu, Kyoto, Japan). Short-chain fatty acids (SCFA) in the rumen fluid was measured on a gas chromatograph (6890, Hewlett-Packard, Palo Alto, CA) with a glass column packed with $5 \%$ Thermon 1000 and $0.5 \% \mathrm{H}_{3} \mathrm{PO}_{4}$ on 80/100 mesh Chromosorb W (Wako Pure Chemical Ltd., Osaka, Japan) as described previously (Tajima et al., 2007). Ammonia and lactate were determined spectrophotometrically using commercially available kits for ammonia (Wako Pure Chemical Industries, Osaka, Japan) and D-/L-lactic acid (Megazyme, Wicklow, Ireland), respectively.

Protozoa were fixed by methylgreen-formalin-saline solution and manually counted under a light microscope (Ogimoto and Imai, 1981). Total DNA for bacterial quantification was extracted from $1 \mathrm{~mL}$ of rumen fluid using the FastPrep FP100A bead beating system with Fast DNA Kit (Qbiogen, Carlsbad, CA), quantified by absorbance on a SmartSpec 3000 (Bio-Rad Laboratories, Hercules, CA); an aliquot containing $10 \mathrm{ng}$ was subjected to real-time PCR analysis. Another portion of the rumen fluid $(0.3 \mathrm{~mL})$ was treated overnight with RNAlater (Ambion, Austin, TX), centrifuged (14,000 $\times g$ for $5 \mathrm{~min}$ ), resuspended in $600 \mu \mathrm{L}$ of RLT buffer (RNeasy mini kit, Qiagen, Carlsbad, CA) with $6 \mu \mathrm{L}$ of $\beta$-mercaptoethanol, and packed in Lysing Matrix E (MP Biomedicals, Irvine, CA) for RNA extraction. The bead beating system was used to extract total RNA with a speed setting of 6 for $2 \mathrm{~min}$. Total RNA was purified with RNeasy mini kit (Qiagen) and quantified by absorbance on a SmartSpec 3000 spectrophotometer. The cDNA was generated from $1 \mu \mathrm{g}$ of purified RNA with the SuperScript First-Strand Synthesis System (Invitrogen, Carlsbad, CA) and used for real-time PCR analysis.

Real-time PCR was performed with a LightCycler system (Roche, Penzberg, Germany) and Platinum 
Table 2. Methane production from cows fed a control diet and a diet supplemented with cashew nut shell liquid (CNSL)

\begin{tabular}{|c|c|c|c|c|c|c|c|c|}
\hline Item & \multicolumn{4}{|c|}{ Trial 1} & \multicolumn{4}{|c|}{ Trial 2} \\
\hline Methane, L/kg of DMI & $\begin{array}{c}44.8^{\mathrm{a}} \\
(100)\end{array}$ & $\begin{array}{c}27.7^{\mathrm{b}} \\
(61.7)\end{array}$ & 3.803 & 0.046 & $\begin{array}{c}38.3^{\mathrm{x}} \\
(100)\end{array}$ & $\begin{array}{r}30.9^{\mathrm{y}} \\
(80.7)\end{array}$ & 1.696 & 0.037 \\
\hline Methane, L/kg of DM apparently digested & $\begin{array}{c}59.3 \\
(100)\end{array}$ & $\begin{array}{c}38.4 \\
(64.7)\end{array}$ & 5.259 & 0.058 & $\begin{array}{c}54.1^{\mathrm{x}} \\
(100)\end{array}$ & $\begin{array}{c}42.4^{\mathrm{y}} \\
(78.4)\end{array}$ & 0.935 & 0.011 \\
\hline Methane, L/kg of OM apparently digested & $\begin{array}{c}61.4 \\
(100)\end{array}$ & $\begin{array}{c}39.7 \\
(64.6)\end{array}$ & 5.576 & 0.060 & $\begin{array}{c}55.5^{\mathrm{x}} \\
(100)\end{array}$ & $\begin{array}{r}43.7^{\mathrm{y}} \\
(78.7)\end{array}$ & 1.806 & 0.023 \\
\hline
\end{tabular}

$\overline{\mathrm{a}, \mathrm{b} ; \mathrm{x}, \mathrm{y}}$ Means within a row with different superscripts differ $(P<0.05)$.

${ }^{1}$ Values in parentheses are relative percentages of methane production in CNSL period to that in control period.

SYBR Green qPCR SuperMix-UDG (Invitrogen). Primers used, thermal conditions, and standard template preparations were as in previous reports (Denman et al., 2007; Koike et al., 2007; Boeckaert et al., 2008). Copy number of methyl coenzyme-M reductase subunit A gene $(\boldsymbol{m c r} \boldsymbol{A})$ and its expression were shown relative to those of $16 \mathrm{~S}$ rDNA. Changes observed due to CNSL feeding in terms of the relative abundances of bacterial species were expressed as $\log _{2}$-fold differences compared with the quantities in the control period. The $\log _{2^{-}}$ fold changes were determined as follows. The relative abundance of the target gene (assayed copy number or transcript of the target gene/assayed copy number or transcript of eubacterial 16S rRNA gene) in the CNSL period was divided by that in the control period and then transformed to $\log _{2}$ form, as described in Khafipour et al. (2009). Target species were 11 representative species of fiber-digesting, formate-, propionate-, and lactate-producing bacteria groups, including Fibrobacter succinogenes, Ruminococcus albus, Ruminococcus flavefaciens, Butyrivibrio fibrisolvens, Treponema bryantii, Prevotella ruminicola, Selenomonas ruminantium, Anaerovibrio lipolytica, Succinivibrio dextrinosolvens, Megasphaera elsdenii, and Streptococcus bovis.

\section{Statistical Analysis}

Repeated measures of daily methane production were checked for adherence to a normal distribution before being used in statistical analysis with ANOVA (SAS version 9.2 via SAS Add-In 4.3 for Microsoft Office; Microsoft Corp., Redmond, WA). Data for nutrient digestibility, energy balance, and rumen fermentation parameters were subjected to the General Linear Model procedure of SAS (SAS Institute Inc., Cary, NC). A $t$ test procedure of SAS was applied to evaluate pairwise comparisons of the treatment. Relative abundance of $m c r A$, its expression, and bacterial species assayed by real-time PCR were analyzed by the $t$-test. Significance was defined at $P<0.05$ and a tendency was declared at $P<0.10$.

\section{RESULTS}

Pellet A, containing only CNSL and silica powder, was not highly palatable to cows that took time to consume the pellet $(2 \mathrm{~h})$. However, pellet B, with several additional ingredients, was favorably accepted and readily consumed $(1 \mathrm{~h})$ by cows. Eventually, total feed intake in terms of DM and GE did not differ between control and treatment periods of each trial (Table 1).

The effect of CNSL on methane production from cows is shown in Table 2. Methane production per unit of DMI decreased $(P<0.05)$ in the CNSL period in both trials 1 and 2 (decreased by 38.3 and $19.3 \%$, respectively). Methane production per unit of apparently digested DM or OM also decreased with CNSL feeding $(P<0.10$ in trial $1 ; P<0.05$ in trial 2$)$.

Changes in nutrient digestibility with CNSL feeding are shown in Table 3. Dry matter and GE digestibility did not differ between the control and CNSL periods in trial 2 but decreased $(P<0.05)$ in the CNSL period of trial 1 (from 75.6 to $72.3 \%$ for DM and from 74.9 to $71.4 \%$ for $\mathrm{GE}$ ). In trial 2 , the digestibility of $\mathrm{CP}$ and NDF tended to increase $(P<0.10)$ when cows were switched to the diet containing CNSL (from 67.4 to $73.1 \%$ for CP, and from 57.3 to $60.8 \%$ for NDF). Thus, the response of nutrient digestibility to CNSL feeding was different between the 2 trials.

Energy balance of the cows fed the diets with and without CNSL is shown in Table 4. Energy loss, as methane emission, decreased in the CNSL period from 9.7 to $6.1 \%$ and from 8.4 to $7.0 \%$ in trials $1(P<$ $0.05)$ and $2(P<0.10)$, respectively. When cows were switched to the diet containing CNSL, feed energy lost to feces increased $(P<0.05)$ from 25.1 to $28.9 \%$ in trial 1 , whereas energy loss as HP increased $(P<0.05)$ from 47.3 to $49.5 \%$ in trial 2 . Retained energy did not differ between the control and CNSL periods in both trials.

Ruminal fermentation products and protozoa population size are shown in Table 5. Ruminal $\mathrm{pH}$ and ammonia nitrogen and lactate concentrations were not affected by CNSL feeding in both trials. Concentra- 
Table 3. Nutrient digestibility in cows fed a control diet and a diet supplemented with cashew nut shell liquid (CNSL)

\begin{tabular}{|c|c|c|c|c|c|c|c|c|}
\hline Item & \multicolumn{4}{|c|}{ Trial 1} & \multicolumn{4}{|c|}{ Trial 2} \\
\hline DM, \% & $75.6^{\mathrm{a}}$ & $72.3^{\mathrm{b}}$ & 0.566 & 0.028 & 7.07 & 73.0 & 1.628 & 0.292 \\
\hline $\mathrm{CP}, \%$ & 68.2 & 63.2 & 1.464 & 0.076 & 67.4 & 73.1 & 1.495 & 0.063 \\
\hline Ether extract, \% & 72.0 & 77.1 & 5.008 & 0.410 & 72.0 & 71.1 & 1.327 & 0.576 \\
\hline NDF, \% & 63.8 & 59.0 & 3.243 & 0.277 & 57.3 & 60.8 & 0.840 & 0.054 \\
\hline
\end{tabular}

${ }^{\mathrm{a}, \mathrm{b}}$ Means within a row with different superscripts differ $(P<0.05)$.

tions of acetate and total SCFA decreased with CNSL feeding in both trials (50.2-50.4 to 31.9-34.6 $\mathrm{mM}$ for acetate and $67.8-67.9$ to $50.9-58.0 \mathrm{~m} M$ for total SCFA; $P<0.05$ for both). The molar proportion of acetate decreased from 74.0 to $74.3 \%$ to 59.9 to $62.8 \%$ when cows were switched to the diet containing CNSL in both trials $(P<0.05)$, whereas that of propionate increased from 12.2 to $14.5 \%$ to 20.5 to $22.9 \%(P<0.10$ in trial 1 and $P<0.05$ in trial 2). Protozoa numbers did not differ between the control and CNSL periods.

The effect of CNSL feeding on ruminal methanogens is shown in Figure 1. The copy number of mcrA decreased when cows were switched to the diet containing CNSL in trial $1(0.32$ to $0.10 \%, P<0.05)$ and trial 2 (0.33 to $0.18 \%, P<0.10$ ). The expression of $m c r A$ relative to total $16 \mathrm{~S}$ rDNA also decreased to $19.1(P<$ $0.01)$ and $59.0 \%(P<0.10)$ in the CNSL period of trials 1 and 2 , respectively.

Changes in rumen bacterial abundance are shown in Figure 2. The relative population size of bacteria decreased with CNSL feeding for fiber-degrading or formate-producing bacteria such as $R$. flavefaciens $(P<0.01), R$. albus $(P<0.05$ in trial 2 only $), B$. fibrisolvens $(P<0.05$ in trial 2 only $)$, and Treponema bryantii $(P<0.05)$, but increased for propionateproducing bacteria, including Prevotella ruminicola $(P$ $<0.01)$, Selenomonas ruminantium $(P<0.10$ in trial 1 and $P<0.05$ in trial 2), Anaerovibrio lipolytica $(P<$ 0.05 in trial 2 only), and Succinivibrio dextrinosolvens $(P<0.05$ in trial 1 only $)$. No notable changes with
CNSL feeding occurred for fibrolytic F. succinogenes. Lactate-producing Streptococcus bovis and propionateproducing Megasphaera elsdenii were not detectable in the experimental cows.

\section{DISCUSSION}

The present study was conducted to test the effect of CNSL on the mitigation of methane production that was found previously in in vitro batch and semicontinuous culture studies (Watanabe et al., 2010) in in vivo feeding trials in cows. By accurately monitoring the methane released from cows in a sophisticated respiration chamber system, we showed that CNSL feeding remarkably decreased methane production per unit of DMI. In particular, a $19.3 \%$ decrease in methane production was achieved without decreasing digestibility in trial 2 using pellet comprising CNSL and several feed ingredients. Of several methane-inhibiting agents that have been proposed, significant decreases have been reported for diet supplementation of lipids (including oils, seeds, and fatty acids), condensed tannins, and monensin (Wedegaertner and Johnson, 1983; Machmüller et al., 2000; McGinn et al., 2004; Carulla et al., 2005; Puchala et al., 2005; Guan et al., 2006; Jordan et al., 2006; Beauchemin et al., 2007a,b, 2009; Odongo et al., 2007; Martin et al., 2008; Tiemann et al., 2008). In these previous studies, methane decreases per unit of DMI in the range of 11.5 to $19.8 \%$ for lipids and 7 to $30 \%$ for monensin were achieved without any decreases

Table 4. Energy balance of cows fed a control diet and a diet supplemented with cashew nut shell liquid (CNSL)

\begin{tabular}{|c|c|c|c|c|c|c|c|c|}
\hline \multirow[b]{2}{*}{ Item } & \multicolumn{4}{|c|}{ Trial 1} & \multicolumn{4}{|c|}{ Trial 2} \\
\hline & Control & CNSL & SEM & $P$-value & Control & CNSL & SEM & $P$-value \\
\hline Urine, \% & 5.0 & 4.3 & 1.774 & 0.694 & 3.5 & 4.2 & 0.817 & 0.528 \\
\hline Methane, \% & $9.7^{\mathrm{a}}$ & $6.1^{\mathrm{b}}$ & 0.830 & 0.048 & 8.4 & 7.0 & 0.417 & 0.072 \\
\hline Heat production, \% & 51.1 & 51.0 & 3.653 & 0.884 & $47.3^{\mathrm{x}}$ & $49.5^{\mathrm{y}}$ & 0.273 & 0.017 \\
\hline
\end{tabular}

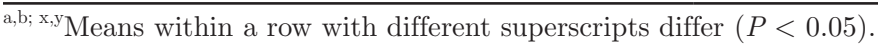


Table 5. Ruminal fermentation products and protozoa number in cows fed a control diet and a diet supplemented with cashew nut shell liquid (CNSL)

\begin{tabular}{|c|c|c|c|c|c|c|c|c|}
\hline \multirow[b]{2}{*}{ Item } & \multicolumn{4}{|c|}{ Trial 1} & \multicolumn{4}{|c|}{ Trial 2} \\
\hline & Control & CNSL & SEM & $P$-value & Control & CNSL & SEM & $P$-value \\
\hline $\mathrm{pH}$ & 7.22 & 7.27 & 0.105 & 0.700 & 6.97 & 7.33 & 0.098 & 0.068 \\
\hline Ammonia, mg of $\mathrm{N} / \mathrm{dL}$ & 12.8 & 12.4 & 1.568 & 0.794 & 14.4 & 10.1 & 1.101 & 0.060 \\
\hline Lactate, $\mathrm{m} M$ & 1.33 & 2.60 & 1.211 & 0.403 & 0.64 & 0.55 & 0.116 & 0.521 \\
\hline Total short-chain FA, $\mathrm{m} M$ & $67.9^{\mathrm{a}}$ & $58.0^{\mathrm{b}}$ & 0.036 & $<0.001$ & $67.8^{\mathrm{x}}$ & $50.9^{\mathrm{y}}$ & 1.253 & 0.005 \\
\hline Acetate, $\mathrm{m} M$ & $50.2^{\mathrm{a}}$ & $34.6^{\mathrm{b}}$ & 2.087 & 0.017 & $50.4^{\mathrm{x}}$ & $31.9^{\mathrm{y}}$ & 1.211 & 0.004 \\
\hline Propionate, $\mathrm{m} M$ & 8.3 & 13.5 & 2.424 & 0.167 & 10.4 & 10.5 & 0.692 & 0.899 \\
\hline Butyrate, $\mathrm{m} M$ & 7.0 & 6.1 & 0.222 & 0.066 & 6.6 & 7.6 & 0.869 & 0.351 \\
\hline Acetate, molar \% & $74.0^{\mathrm{a}}$ & $59.9^{\mathrm{b}}$ & 3.210 & 0.048 & $74.3^{\mathrm{x}}$ & $62.8^{\mathrm{y}}$ & 0.946 & 0.007 \\
\hline Propionate, molar \% & 12.2 & 22.9 & 3.569 & 0.095 & $14.5^{\mathrm{x}}$ & $20.5^{\mathrm{y}}$ & 1.009 & 0.027 \\
\hline Butyrate, molar \% & 10.1 & 10.5 & 0.207 & 0.227 & 9.7 & 15.0 & 1.485 & 0.071 \\
\hline Total protozoa, log number/mL & 6.31 & 6.25 & 0.103 & 0.614 & 5.71 & 5.72 & 0.036 & 0.720 \\
\hline
\end{tabular}

$\overline{\mathrm{a}, \mathrm{b} ; \mathrm{x}, \mathrm{y}}$ Means within a row with different superscripts differ $(P<0.05)$.

in feed intake or nutrient digestibility in cattle. Comparisons of the reported methane decrease rates and the values obtained in the present study $(19.3 \%)$ demonstrate that CNSL is comparable or superior to lipids and monensin, which were the previously proposed methane-inhibiting agents for use as feed supplements.

Feeding CNSL decreased the relative copy number and expression of $m c r A$ in the rumen (Figure 1), which is crucial for ruminal methanogenesis (Luton et al., 2002). Therefore, the decrease of methane achieved by CNSL feeding seems to be partially due to the direct inhibition of methanogens, including the inhibition of growth and methanogenic activity. Although total methanogens are not necessarily correlated to the amount of transcript of $m c r A$ and actual methane production (Machmüller et al., 2003; Guo et al., 2008), the present results indicate that responses of all parameters relating to methanogenesis ( $m c r A$ copy number, $m c r A$ transcripts, and methane production) to CNSL feeding coincide well. However, other potential inhibitory mechanisms remain to be explored. The shortage of formate and hydrogen that are substrates for methanogenesis can be considered, because $B$. fibrisolvens, Treponema bryantii, and 2 ruminococcal species $(R$. albus and $R$. flavefaciens; Figure 2) known to be active formate and hydrogen producers (Boone et al., 1989; Paillard et al., 2007) showed decreased relative abundance with CNSL feeding. The response of rumen fungi (also formate and hydrogen producers) to CNSL also needs to be examined.

The decrease of methane production had a notable effect on energy balance, as energy loss to methane emissions decreased in trials 1 (9.7 to $6.1 \%)$ and $2(8.4$ to $7.0 \%)$. However, in trial 1 , digestibility decreased for DM, GE, OM, and CP, possibly because of the de-
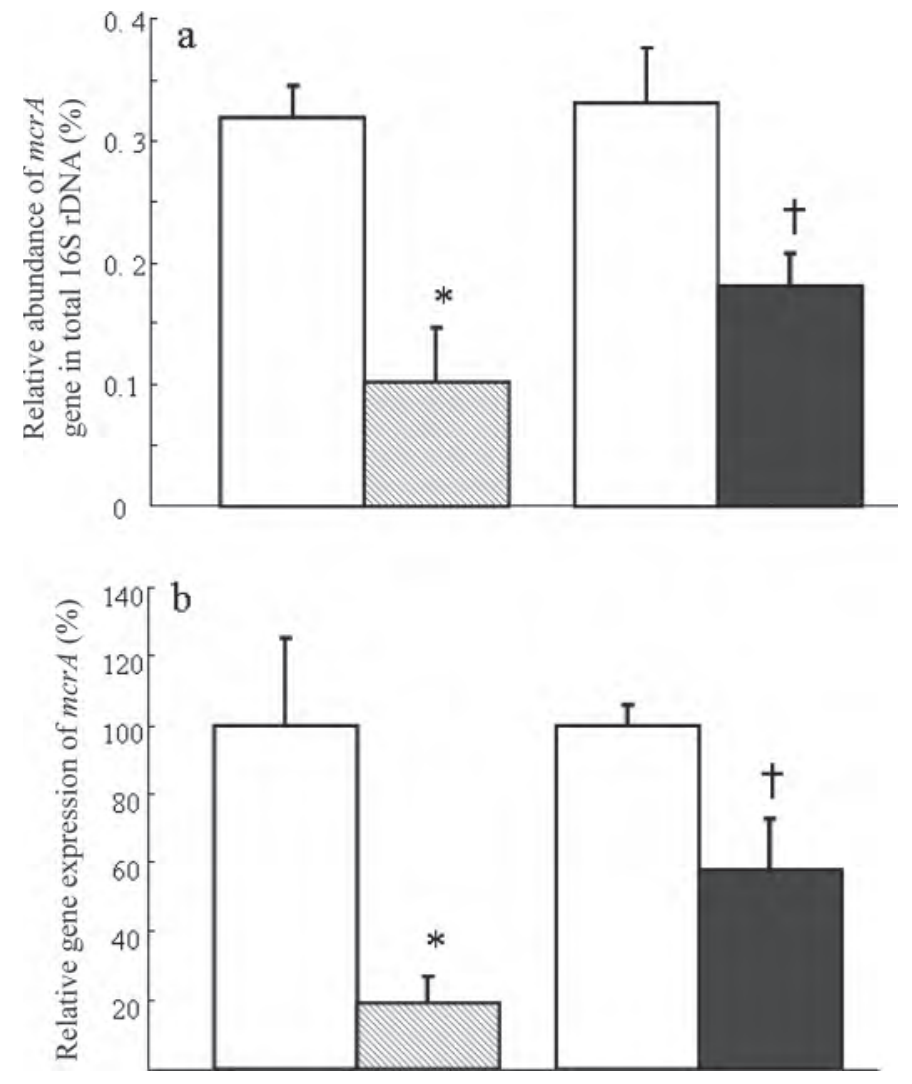

Figure 1. Relative abundance of methyl coenzyme-M reductase subunit A gene ( $m c r A$ ) based on (a) copy number and (b) transcript of total $16 \mathrm{~S}$ rDNA. The values in cashew nut shell liquid (CNSL) period of trials 1 (shaded bars) and 2 (black bars) differ from those in control period (white bars) at ${ }^{*} P<0.05$ and $\dagger P<0.10$. Error bar shows standard error of the mean. 


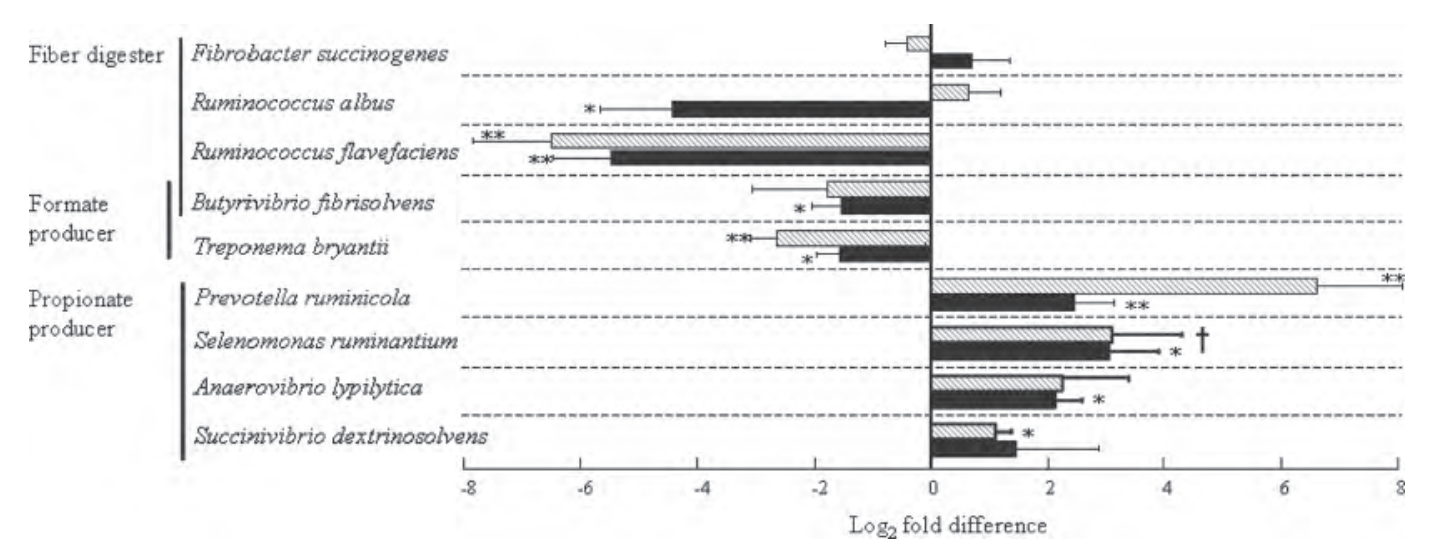

Figure 2. $\log _{2}$ fold changes in rumen bacterial population in cashew nut shell liquid (CNSL) period of trials 1 (shaded bars) and 2 (black bars) compared with control period. Changes differ at ${ }^{* *} P<0.01,{ }^{*} P<0.05$, and $\dagger P<0.10$. Error bar shows standard error of the mean.

creased abundance of some important bacteria (e.g., 2 ruminococcal species and $B$. fibrisolvens) with CNSL feeding. An increase of unabsorbed nutrients resulted in increased energy loss to feces. Therefore, decreased energy loss to methane by CNSL feeding (9.7 to 6.1\%) was almost negated by the increased energy loss to feces (25.1 to $28.9 \%$ ) in trial 1, and no difference in energy retention due to CNSL feeding was observed in trial 1. In trial 2 , digestibility was not affected by CNSL feeding and HP increased $(P<0.05)$, resulting in equal efficiency for energy retention in the control and CNSL periods. The increment of HP under methane-decreased conditions when cows were fed monensin was not clearly explained in Wedegaertner and Johnson (1983). Although the mechanism involved in the increased HP observed in trial 2 is not clarified here, $\mathrm{CO}_{2}$ not utilized in ruminal methanogenesis might have affected the calculated HP; that is, HP was overestimated because the formula (see Materials and Methods) uses the volume of $\mathrm{CO}_{2}$ arising not only from expiration but also from ruminal fermentation. Thus, $\mathrm{CO}_{2}$ generated in ruminal fermentation but not utilized for methanogenesis might have contributed to the increased HP. Another possible factor to increase HP is the uncoupling action of anacardic acid of CNSL against oxidative phosphorylation in animal body tissues, as previously reported in rat hepatic mitochondria (Toyomizu et al. 2000). This may be another source of HP in CNSL-fed cattle.

Supplementation with CNSL in semicontinuous culture enhanced propionate production through the selection of propionate-producing bacteria (Watanabe et al., 2010). Such propionate enhancement was indicated in an early batch culture study using anacardic acid, a main constituent of CNSL (Van Nevel et al., 1971). We confirmed the increase in the proportion (but not concentration) of propionate in cattle rumen by CNSL feeding. The concomitant increase of representative pro- pionate-producing bacteria shows that similar changes in the bacteria population occur in cattle rumen. Because propionate serves as an alternate electron sink to methane, the enhanced propionate level could play an indirect role in decreased ruminal methanogenesis (Russell and Strobel, 1989). However, the persistency of these microbial and fermentation changes must be confirmed in a longer feeding experiment.

Monitoring of the rumen bacterial abundance indicated the reduction of some fibrolytic bacteria $(R$. flavefaciens and B. fibrisolvens) with CNSL feeding. However, F. succinogenes maintained its numbers even with CNSL feeding. The stability of $F$. succinogenes, the most important species in fiber digestion (Shinkai et al., 2010), might have resulted in no difference in NDF digestibility between the control and CNSL periods. The abundance of fibrolytic bacteria is supported by differences in sensitivity among species determined in pure culture by Watanabe et al. (2010), who found that $F$. succinogenes is less sensitive to CNSL than the highly sensitive $R$. flavefaciens and B. fibrisolvens.

It is important to consider the reasons for the differences between the 2 CNSL pellets tested in the present study in responses regarding methane production, digestibility, and bacterial abundance. The composition of the CNSL pellet vehicle may be the main factor for the differences in response; that is, pellet A contained only silica powder (trial 1) and could be easily diffused in the rumen, whereas pellet B had several ingredients (trial 2) and might not be as easily diffused. In this respect, rumen microbial and metabolic responses to CNSL would be milder for the use of pellet B, which may explain why the decrease in methane production occurred to a lesser extent in trial 2 than in trial 1 . Indeed, the greater decrease of methane production in trial 1 was accompanied by decreased digestibility, which is likely attributed to the growth inhibition of 
important bacteria with faster and greater diffusion of CNSL from pellet A. This hypothesis, however, needs to be experimentally confirmed and appropriate feeding procedures for each pellet need to be defined. Such actions could contribute to further improvement of the product and its wider application.

\section{CONCLUSIONS}

Although a limited number of animals were used in this study, the accurate gas monitoring system confirmed the in vivo effect of CNSL on mitigation of methane production from cattle without adversely affecting feed digestion when CNSL was fed via a properly formulated pellet. The rate of methane decrease, feed digestibility, and bacterial population in response to CNSL feeding differed between the pellet types tested. The advantages of CNSL feeding should be further assessed because CNSL shows potential to decrease methane and increase propionate, thus improving feed conversion efficiency. However, energy retention could not be linked to feed conversion efficiency in the present study. Further studies should be performed to validate the efficacy of CNSL under various feeding conditions, and the economic advantage of a long-term CNSL feeding should be evaluated for its wider use in ruminants.

\section{ACKNOWLEDGMENTS}

The authors appreciate the financial support to the present study from Japanese Ministry of Agriculture, Forestry and Fisheries through the program "Research and Development Projects for Application in Promoting New Policy of Agriculture Forestry and Fisheries."

\section{REFERENCES}

AOAC. 1990. Official Methods of Analysis. 15th ed. Association Official Analytical Chemists, Arlington, VA.

Beauchemin, K. A., S. M. McGinn, C. Benchaar, and L. Holtshausen. 2009. Crushed sunflower, flax, or canola seeds in lactating dairy cow diets: Effects on methane production, rumen fermentation, and milk production. J. Dairy Sci. 92:2118-2127.

Beauchemin, K. A., S. M. McGinn, T. F. Martinez, and T. A. McAllister. 2007a. Use of condensed tannin extract from quebracho trees to reduce methane emissions from cattle. J. Anim. Sci. 85:19901996.

Beauchemin, K. A., S. M. McGinn, and H. V. Petit. 2007b. Methane abatement strategies for cattle: Lipid supplementation of diets. Can. J. Anim. Sci. 87:431-440.

Boeckaert, C., B. Vlaeminck, V. Fievez, L. Maignien, J. Diikstra, and N. Boon. 2008. Accumulation of trans $\mathrm{C}_{18: 1}$ fatty acids in the rumen after dietary algal supplementation is associated with changes in the Butyrivibrio community. Appl. Environ. Microbiol. 74:6923-6930.

Boone, D. R., R. L. Johnson, and Y. Liu. 1989. Diffusion of the interspecies electron carriers $\mathrm{H}_{2}$ and formate in methanogenic ecosystems and its implications in the measurement of $\mathrm{K}_{m}$ for $\mathrm{H}_{2}$ or formate uptake. Appl. Environ. Microbiol. 55:1735-1741.
Brouwer, E. 1965. Report of sub-committee on constants and factors. Pages 441-443 in Energy Metabolism of Farm Animals. Academic Press, London, UK.

Carulla, J. E., M. Kreuzer, A. Machmüller, and H. D. Hess. 2005. Supplementation of Acacia mearnsii tannins decreases methanogenesis and urinary nitrogen in forage-fed sheep. Aust. J. Agric. Res. 56:961-970.

Denman, S. E., N. W. Tomkins, and C. S. McSweeney. 2007. Quantitation and diversity analysis of ruminal methanogenic populations in response to the antimethanogenic compound bromochloromethane. FEMS Microbiol. Ecol. 62:313-322.

Edwards, J. E., N. R. McEwan, N. McKain, N. Walker, and R. J. Wallace. 2005. Influence of flavomycin on ruminal fermentation and microbial populations in sheep. Microbiology 151:717-725.

FAO. 2007. Livestock's Long Shadow. Part IV. Livestock's role in climate change and air pollution. Accessed May 29, 2012. ftp://ftp. fao.org/docrep/fao/010/a0701e/a0701e03.pdf.

Guan, H., K. M. Wittenberg, K. H. Ominski, and D. O. Krause. 2006. Efficacy of ionophores in cattle diets for mitigation of enteric methane. J. Anim. Sci. 84:1896-1906.

Guo, Y. Q., J. X. Liu, Y. Lu, W. Y. Zhu, S. E. Denman, and C. S. McSweeney. 2008. Effect of tea saponin on methanogenesis, microbial community structure and expression of $m c r A$ gene, in cultures of rumen micro-organisms. Lett. Appl. Microbiol. 47:421-426.

Hook, S. E., A. D. Wright, and B. W. McBride. 2010. Methanogens: Methane producers of the rumen and mitigation strategies. Archaea 2010:945785.

Iwasaki, K., T. Haryu, R. Tano, F. Terada, M. Itho, and K. Kameoka. 1982. New animal metabolism facility especially the description of respiration apparatus. Bull. Nat. Inst. Anim. Ind. 39:41-78.

Jordan, E., D. K. Lovett, F. J. Monahan, J. Callan, B. Flynn, and F. P. O'Mara. 2006. Effect of refined coconut oil or copra meal on methane output and on intake and performance of beef heifers. J. Anim. Sci. 84:162-170.

Khafipour, E., S. Li, J. C. Plaizier, and D. O. Krause. 2009. Rumen microbiome composition determined using two nutritional models of subacute ruminal acidosis. Appl. Environ. Microbiol. 75:7115-7124.

Koike, S., H. Yabuki, and Y. Kobayashi. 2007. Validation and application of real-time polymerase chain reaction assays for representative rumen bacteria. Anim. Sci. J. 78:135-141.

Kubo, I., H. Muroi, and M. Himejima. 1993. Structure-antibacterial activity relationships of anacardic acids. J. Agric. Food Chem. 41:1016-1019.

Luton, P. E., J. M. Wayne, R. J. Sharp, and P. W. Riley. 2002. The mcrA gene as an alternative to $16 \mathrm{~S}$ rRNA in the phylogenetic analysis of methanogen populations in landfill. Microbiology 148:3521-3530.

Machmüller, A., D. A. Ossowski, and M. Kreuzer. 2000. Comparative evaluation of the effects of coconut oil, oilseeds and crystalline fat on methane release, digestion and energy balance in lambs. Anim. Feed Sci. Technol. 85:41-60.

Machmüller, A., C. R. Soliva, and M. Kreuzer. 2003. Effect of coconut oil and defaunation treatment on methanogenesis in sheep. Reprod. Nutr. Dev. 43:41-55.

Martin, C., J. Rouel, J. P. Jouany, M. Doreau, and Y. Chilliard. 2008 Methane output and diet digestibility in response to feeding dairy cows crude linseed, extruded linseed, or linseed oil. J. Anim. Sci. $86: 2642-2650$.

McGinn, S. M., K. A. Beauchemin, T. Coates, and D. Colombatto. 2004. Methane emissions from beef cattle: Effects of monensin, sunflower oil, enzymes, yeast, and fumaric acid. J. Anim. Sci. $82: 3346-3356$

NARO (National Agriculture and Food Research Organization). 2006. Japanese feeding standard for dairy cattle. Japan Livestock Industry Association (in Japanese). Central Association of Livestock Industry, Tokyo, Japan.

Odongo, N. E., R. Bagg, G. Vessie, P. Dick, M. M. Or-Rashid, S. E. Hook, J. T. Gray, E. Kebreab, J. France, and B. W. McBride. 2007. Long-term effects of feeding monensin on methane production in lactating dairy cows. J. Dairy Sci. 90:1781-1788. 
Ogimoto, K., and S. Imai. 1981. Atlas of Rumen Microbiology. Japan Scientific Societies Press, Tokyo, Japan.

Paillard, D., N. McKain, L. C. Chaudhary, N. D. Walker, F. Pizette, I. Koppova, N. R. McEwan, J. Kopecný, P. E. Vercoe, P. Louis, and R. J. Wallace. 2007. Relation between phylogenetic position, lipid metabolism and butyrate production by different Butyrivibrio-like bacteria from the rumen. Antonie van Leeuwenhoek 91:417-422.

Puchala, R., B. R. Min, A. L. Goetsch, and T. Sahlu. 2005. The effect of a condensed tannin-containing forage on methane emission by goats. J. Anim. Sci. 83:182-186.

Russell, J. B., and H. J. Strobel. 1989. Effect of ionophores on ruminal fermentation. Appl. Environ. Microbiol. 55:1-6.

Shibata, M., and F. Terada. 2010. Factors affecting methane production and mitigation in ruminants. Anim. Sci. J. 81:2-10.

Shinkai, T., T. Ueki, and Y. Kobayashi. 2010. Detection and identification of rumen bacteria constituting a fibrolytic consortium dominated by Fibrobacter succinogenes. Anim. Sci. J. 81:72-79.

Tajima, K., I. Nonaka, K. Higuchi, N. Takusari, M. Kurihara, A. Takenaka, M. Mitsumori, H. Kajikawa, and R. I. Aminov. 2007. Influence of temperature and humidity on rumen bacterial diversity in Holstein heifers. Anaerobe 13:57-64.

Tiemann, T. T., C. E. Lascano, H. R. Wettstein, A. C. Mayer, M. Kreuzer, and H. D. Hess. 2008. Effect of the tropical tannin-rich shrub legumes Calliandra calothyrsus and Flemingia macrophylla on methane emission and nitrogen and energy balance in growing lambs. Animal 2:790-799.
Toyomizu, M., K. Okamoto, T. Ishibashi, Z. Chen, and T. Nakatsu. 2000. Uncoupling effect of anacardic acids from cashew nut shel oil on oxidative phosphorylation of rat liver mitochondria. Life Sci. 66:229-234.

US EPA. 2005. Greenhouse Gas Mitigation Potential in U.S. Forestry and Agriculture. EPA 430-R-05-006, November 2005. United States Environmental Protection Agency, Washington, DC. http://www. epa.gov/sequestration/pdf/greenhousegas2005.pdf.

Van Nevel, C. J., D. I. Demeyer, and H. K. Henderickx. 1971. Effect of fatty acid derivatives on rumen methane and propionate in vitro. Appl. Microbiol. 21:365-366.

Van Soest, P. J., J. B. Robertson, and B. A. Lewis. 1991. Methods for dietary fiber, neutral detergent fiber, and nonstarch polysaccharides in relation to animal nutrition. J. Dairy Sci. 74:3583-3597.

Watanabe, Y., R. Suzuki, S. Koike, K. Nagashima, M. Mochizuki, R. J. Forster, and Y. Kobayashi. 2010. In vitro evaluation of cashew nut shell liquid as a methane-inhibiting and propionate-enhancing agent for ruminants. J. Dairy Sci. 93:5258-5267.

Wedegaertner, T. C., and D. E. Johnson. 1983. Monensin effects on digestibility, methanogenesis and heat increment of a cracked cornsilage diet fed to steers. J. Anim. Sci. 57:168-177.

Wright, A. D., A. J. Williams, B. Winder, C. T. Christophersen, S. L. Rodgers, and K. D. Smith. 2004. Molecular diversity of rumen methanogens from sheep in Western Australia. Appl. Environ. Microbiol. 70:1263-1270. 